\title{
What has caused the fall in stroke admissions during the COVID-19 pandemic?
}

\author{
Richard Perry $^{1,2} \oplus^{\circ} \cdot$ Azra Banaras $^{1,2} \cdot$ David J. Werring $^{1,2} \cdot$ Robert Simister $^{1,2}$
}

Received: 17 June 2020 / Revised: 25 June 2020 / Accepted: 26 June 2020 / Published online: 29 June 2020

c) Springer-Verlag GmbH Germany, part of Springer Nature 2020

During the current COVID-19 pandemic there has been a decline in stroke admissions in centres all over the world $[1,2]$ and no doubt this phenomenon has contributed to the sharp fall in the number of patients attending Emergency Departments in England during March 2020 [3]. The explanation remains unclear. Hypotheses fall into two main categories. Either the incidence of stroke has declined during this period, or a higher proportion of patients who have strokes are never reaching stroke services [2]. We reasoned that any change in the spectrum of stroke severity in patients presenting during the pandemic might yield important clues to distinguish between these two possibilities, as follows.

If the main explanation is that a lower proportion of patients having a stroke are finding their way into stroke beds, then probably most of that decline will have been among those with the mildest strokes. These are the patients most likely to decide to manage their stroke at home, perhaps for fear of the risk of contracting COVID-19 whilst in hospital. They are the most likely to have their neurological symptoms missed at a time of severe respiratory illness from the virus, or to be turned away from overstretched emergency services rather than being directed into the stroke pathway [4]. Finally, minor stroke symptoms are probably more likely to be overlooked in residents of care homes. On the other hand putative mechanisms for a decline in stroke incidence, such as reduced strain whilst people are not at work or lower levels of pollution [3], would not necessarily impact on strokes of any particular severity.
We examined stroke severity in patients with a final diagnosis of acute stroke who were admitted to the Hyperacute Stroke Unit at UCL Hospitals, which provides the comprehensive stroke service for North Central London in the United Kingdom.

Figure 1 shows the distribution of stroke severities (using the National Institutes of Health Stroke Scale) in admissions to our Hyperacute Stroke Unit for two 40-day periods: before the decline in emergency admissions in England [3] (1st February to 12th March, blue triangles) and after it (1st April to 11th May 2020, red circles). The decline in the number of patients admitted with mild strokes (NIHSS $\leq 5$ ) was far more dramatic than was seen for moderate or severe strokes (NIHSS > 5). It seems unlikely that a fall in the true incidence of stroke would have been so strongly biased towards mild strokes, and more plausible that the major factor driving this decline is that patients with mild strokes were no longer reaching our service during the second period.

If patients with minor strokes are staying away from stroke inpatient services, as our data appear to suggest, then this is a worrying conclusion. Without treatment about $10 \%$ of these patients will have a recurrent stroke within a week [5]. On the other hand, the risk of catching the infection whilst in hospital is likely to be very low [6]. The public health message is clear: individuals who think that they may be having a stroke, regardless of symptom severity, are much better off calling for an ambulance than staying at home.

Richard Perry

richard.perry2@nhs.net

1 UCL Hospitals NHS Foundation Trust, London, UK

2 Stroke Research Centre, UCL Queen Square Institute of Neurology, University College London, London, UK 


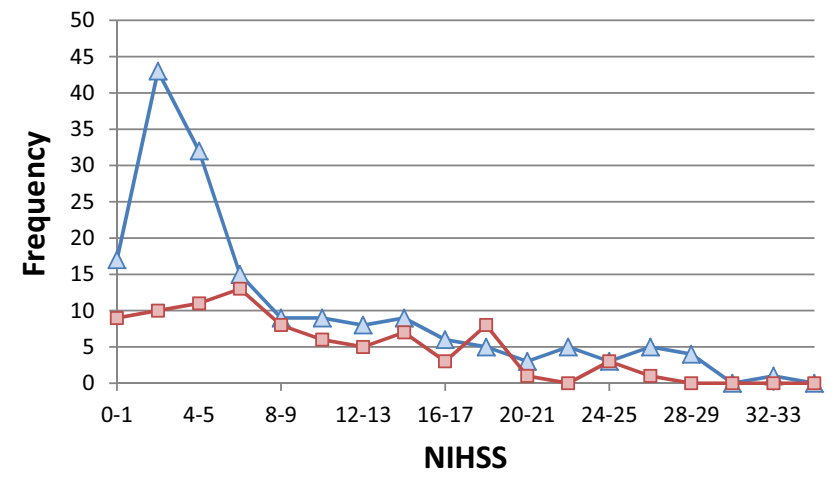

Fig. 1 Distribution of National Institutes of Health Stroke Scale (NIHSS) for patients presenting in the 40 days from 1st February 2020 (blue triangles, total 175 patients) and for those presenting during the 40 days from 1 st April (red circles, total 84 patients). The NIHSS is a score between 0 and 42 representing the degree of neurological impairment, higher scores representing more severe strokes. Bin width $=2$

Acknowledgements This work was undertaken at UCL Hospitals/ UCL which receives a proportion of funding from the Department of Health's National Institute for Health Research (NIHR) Biomedical Research Centres funding scheme.

\section{Compliance with ethical standards}

Conflicts of interest $\mathrm{RP}$ and $\mathrm{AB}$ have no interests to declare. RS shares the role of Clinical Director for Stroke in London. DJW has received personal fees from Bayer, Alnylam and Portola, not related to the work presented here.

Ethical standard statement The data reported were collected routinely for national audit purposes and so did not require formal ethical review.

\section{References}

1. Markus HS, Brainin M (2020) COVID-19 and stroke—a global World Stroke Organization perspective. Int J Stroke 15:361-364. https://doi.org/10.1177/1747493020923472

2. de Sousa DA, Sandset EC, Elkind MS (2020) The curious case of the missing strokes during the COVID-19 pandemic. Stroke. https ://doi.org/10.1161/STROKEAHA.120.030792

3. Public Health England (2020) Emergency Department Syndromic Surveillance System Week 23 Public Health England. https ://assets.publishing.service.gov.uk/government/uploads/system/ uploads/attachment_data/file/891440/EDSSSBulletin2020wk2 3.pdf. Accessed 17 Jun 2020

4. Rudilosso S, Laredo C, Vera V, Vargas M, Renu A, Llull L, Obach V, Amaro S, Urra X, Torres F, Jimenez-Fabrega FX, Chamorro A (2020) Acute stroke care is at risk in the era of COVID-19. Stroke. https://doi.org/10.1161/STROKEAHA.120.030329

5. Coull AJ, Lovett JK, Rothwell PM (2004) Population based study of early risk of stroke after transient ischaemic attack or minor stroke: implications for public education and organisation of services. Br Med J 328:326

6. Treibel TA, Manisty C, Burton M, McKnight A, Lambourne J, Augusto JB, Couto-Parada X, Cutino-Moguel T, Noursadeghi M, Moon JC (2020) COVID-19: PCR screening of asymptomatic health-care workers at London hospital. Lancet 395:1608-1610 